\title{
Numerical study of air staging in a coke oven heating system
}

\author{
Jakub Poraj ${ }^{1} \cdot$ Stanislaw Gamrat $^{1} \cdot$ Jakub Bodys $^{1} \cdot$ Jacek Smolka $^{1} \cdot$ \\ Wojciech Adamczyk ${ }^{1}$
}

Received: 3 December 2015/ Accepted: 4 June 2016/Published online: 22 June 2016

(c) The Author(s) 2016. This article is published with open access at Springerlink.com

\begin{abstract}
The air staging to combustion approach introduced to a coke oven heating system as a primary method of nitrogen oxide (NO) formation reduction is considered in this paper. To numerically investigate the thermal and prompt NO formation, a heating flue model representing the most popular Polish coke oven battery was used. The model was developed and experimentally validated as a transient coupled model for the representative heating flue and the two coke ovens. Numerical simulations were performed to estimate the amount of NO passing into the atmosphere during the operation of such a heating system with and without the secondary air inlets. Various strategies for the secondary air distribution along the flue gas flow as well as the secondary air velocity were studied. The results of the numerical investigation demonstrated the substantial positive effect of the considered air staging on NO formation reduction.
\end{abstract}

Keywords Coke oven battery $\cdot$ Heating flue $\cdot$ Coke oven gas $\cdot$ NO reduction $\cdot$ Air staging

Electronic supplementary material The online version of this article (doi:10.1007/s10098-016-1234-8) contains supplementary material, which is available to authorized users.

Jacek Smolka

jacek.smolka@polsl.pl

1 Institute of Thermal Technology, Silesian University of Technology, Konarskiego 22, 44-100 Gliwice, Poland

\section{Introduction}

Considering its emission and significantly toxic characteristics, nitrogen oxide (NO) pollution represents an important issue in modern combustion technologies. This substance contributes to smog formation, causes plant decay and negatively impacts living creatures. A vast majority of the emitted NO is created by burning fossil fuels which cause the crucial impact on the ecological area. The emission limitations of NO are also related to the economical area. An interesting analysis concentrated on an influence of the investment part on the air quality was presented in the literature (Panepinto et al. 2014). Further analysis which concerned the time variable emission was provided by Kumar et al. (2016). In that work, a global perspective of various emission sectors was studied. An illustration of the European Union developed on the basis of $\mathrm{NO}$ and $\mathrm{SO}_{2}$ emission coming from Spain was presented by García-Gusano et al. (2015). The economic aspects were investigated by those authors, and conclusions based on renewable energy sources were presented. Similar analysis focused on the Polish energetic sector was performed as well. Namely, Ilamathi et al. (2013) analysed renewable sources located in sea-shore district of Poland. Nevertheless, the investigation of this character was not presented for other districts of Poland. However, according to Houshfar et al. (2014), the emission due to pyrolisis and combustion processes takes a position of serious pollutant in such an industrial sectors as those located in the south of Poland.

Currently, NO emission is legally limited in many countries around the world. Each novelisation of greenhouse and toxic gas emission limits in countries of the European Union provides a significant restriction on the permitted amount of pollution released into the 
atmosphere, as defined in Directive 2001/80/EC in the Official Journal of the European Communities. For example, large combustion plants supplied with hard coal, where the nominal thermal power exceeds $500 \mathrm{MW}$, are obligated not to emit more than $500 \mathrm{mg} / \mathrm{Nm}^{3}$ of $\mathrm{NO}$ with a mole fraction of the oxide in the flue gases of $6 \%$. The most tangible restriction (binding since 1 January, 2016) sets the standard for $\mathrm{NO}$ emission to $200 \mathrm{mg} / \mathrm{Nm}^{3}$.

The problem of $\mathrm{NO}$ emission has been studied in numerous works. Loffler et al. (2006) considered the contribution of thermal and prompt mechanisms of NO generation on the overall $\mathrm{NO}$ emission for the premixed combustion of natural gas. The result of that work was a simplified model of thermal NO formation. Ma et al. (2009) developed biomass co-firing models and described the effects of this process on NO emission. In the work of Miltner et al. (2008), Computational Fluid Dynamics (CFD) methods were used to optimise the work of a solid biomass combustor and predicted the fuel-NO emission. Zhou et al. (2014) analysed the influence of the primary air pipe structure on the NO emission of a swirl burner. A numerical study of NO formation from turbulent leanpremixed flames was investigated by Kang et al. (2009). They used a flamelet model to represent the complex turbulence-chemistry interaction. In the work of Ilamathi et al. (2013), the authors performed an experimental study and artificial neural network computations to estimate NO emission from a pulverised coal-fired boiler. The results of experimental research on NO formation in a PF oxy-fuel firing system are described in the work of Ndibe et al. (2013). In the study of Boyd Fackler et al. (2011), both experimental and numerical investigations were performed for a high-intensity, single-jet, stirred reactor to predict the amount of emitted NO.

Substantial changes in NO emission limits require efficient methods for reducing NO formation. Different approaches have been developed to this end. In general, these methods can be divided into primary and secondary methods. Primary methods for decreasing NO emission (Annamalai and Puri 2006) include rearranging the combustion process itself to obtain a lower amount of NO passing into the atmosphere. Operations of this type are widely described in the literature. In the works of Nimmo et al. (2008), the reburning method, defined as a three-stage combustion process, was presented. A decrease in $\mathrm{NO}$ emission based on the use of this approach was achieved by reducing the maximum temperature within the gas domain. A similar method was considered in the work of Hampartsoumian et al. (2003), where the reburning fuel was a pulverised coal. The use of overfire air to achieve combustion in a tangentially fired utility boiler was studied in the work of Diez et al. (2008). The authors developed and then validated a mathematical model that can extend analysis of the implementation of the NO emission reduction using primary methods. Cozzi and Coghe (2012) applied air staging to swirling burner. The authors considered a non-premixed natural gas combustor under overall lean conditions. Air staging and swirl burners were also a main topic of the work of $\mathrm{Li}$ et al. (2015). In that work, various secondary air mass flow rates and their influence on carbon oxide and NO emissions were considered. The concept of air staging in large-scale industrial boiler has been widely discussed by Higgins et al. (2010). The authors proposed the RROFA technology for a reduction of $\mathrm{NO}$ emission to follow environmental regulations. The work of Wang et al. (2014) shows the possible application of a co-firing process with air staging on the NO emission reduction using advanced CFD models.

The main source of NO pollution is the heavy and power industries. One of the most important branches of heavy industry is coke production. Coke is a fuel used to supply blast furnaces and contributes to a major part of worldwide steel production. This fuel is obtained via the coking process, namely by heating hard coal without air access. The thermal energy required by this process is generally provided through a coke oven gas (COG) or blast furnace gas (BFG). In Polish coke plants, COG is mainly used as a byproduct of the coking process. Therefore, a significant amount of $\mathrm{NO}$, i.e. $400 \mathrm{~g} / \mathrm{Mg}$ to $950 \mathrm{~g} / \mathrm{Mg}$ of coke, is formed during coke plant operation (Report 2005). This range depends on the battery type, age, technical state and applied emission reduction technologies.

The problem of NO pollution in the coking industry has already been studied. Jin et al. (2013) investigated the influence of BFG staging on NO emission. The authors performed numerical computations on a coupled model of a coke oven furnace and two halves of coking chambers. Their results showed that the staging fuel (as well as its distribution among specific inlets) has a large impact on the resulting NO pollution. Another example is the work of Weiss et al. (2012), in which NO emission reduction in a coke oven furnace was also investigated. These authors investigated the influence of BFG staging enriched with natural and converter gases.

Unfortunately, other than the idea of external flue gas recirculation, modifications to the coke oven battery in operation aimed at NO reduction cannot be easily implemented due to the construction limitations of plants. Namely, an approach that involves air staging requires additional inlets at selected levels. This means that a rebuilding of the furnace wall is necessary to include new air ducts. The wall is made of silica brick, and its operating temperature cannot exceed $1273 \mathrm{~K}$ during the coking process. Alternatively, longer processing times than indicated by coking technology exclusion of the combustion process lead to a non-permissible decrease in the wall 
temperature. Such a temperature drop causes a degradation of the mechanical properties of the brick and consequently results in the destruction of the entire construction. This has a crucial impact on the realistic possibilities of the air staging implementation when considering a coke plant in operation. Taking the cost aspects of this technology into account, it is worth noting that reburning technologies are still a more expensive primary method of NO reduction. Therefore, the idea of staging air combustion seems to be a very interesting approach.

The objective of this paper is to investigate air staging combustion in the most modern coke oven battery (PWR63 ) on the Polish coke production market. The investigated type of coke oven is yet to be studied in terms of NO emission reduction. In addition, this technology of an oxidizer supply implemented in, for example, steam boilers cannot be directly compared with this application because of the different combustion conditions. The main differences include the geometry of the combustion chamber resulting in different values of the velocity and turbulence intensity fields and the manner of heat transfer. However, the most important difference is in the air-fuel mixture inlets because simple rectangular ducts are applied in the coke oven battery, and low-emission swirl burners are used in steam boilers.

This paper is also important for Polish emission reduction policy because Poland produces coke at one of the highest rates in the EU, contributing almost $25 \%$. Many reports (for example, Report of the Polish Ministry of Environment, 2005) show that the emission of harmful substances, including NO, from coke oven batteries is a serious problem. That document also indicated that air staging technologies represent a potentially effective way to decrease such emissions.

To perform this study, a fully developed model of the combustion chamber in the above-mentioned unit was used. The model was first formulated and subsequently experimentally validated in a transient coupled form. The model includes two coke ovens and a heating flue as a representative domain of the entire coke oven battery (Smolka et al. 2016). For this study, the model of the heating flue was used only as described in the work of Smolka et al. (2014). However, the boundary conditions were taken from the transient coupled model and then time averaged. The model was completed with a number of staging air inlets located in the vertical walls between the heating flue and the coke oven furnace.

To apply the most efficient strategy for staging air combustion, various approaches of secondary air delivery are analysed in this work, including an approach considering the height of the inlet location in the wall and a combination of the parallel operation of the air streams and the air velocity at the inlets. Following numerous computations, the most promising distribution of the secondary air in the proposed additional inlets was found. The emission reduction obtained under the final solution is substantial when compared to the case without air staging.

\section{Model of gas combustion in coke oven furnaces}

\section{Physical model}

A coke oven battery is formed by a series of heating flues and coking chambers that are placed in rows to maximise the heat transfer rate. The battery heating system consists of a number of furnaces with upward and downward flues. To endure the high temperatures, the heating walls of the coke oven battery are made of silica brick.

The considered heating flue is supplied by the purified COG and air from the bottom inlets, as shown in Fig. 1. Moreover, to consider the air staging in this paper, the secondary air inlets were located at five levels of the vertical wall that separated the neighbouring flues.

In this system, the air and fuel are introduced into an upward flue. Then, the air-fuel mixture combusts, and the hot flue gases flow upward, pass the bridge window and flow down along a downward flue. The flue gas outlet is located at the bottom of the downward flue. The flue gas flow increases the temperature of the heating walls via convection and radiation. Then, heat is transferred to a coking chamber through the wall. A schematic view of the heating flue is shown in Fig. 1.

The required temperature of the coke in the centre of the coking chamber at the end of the coking cycle is approximately $1273 \mathrm{~K}$. Thus, the temperature of the flue gases should be in the range of $1673 \mathrm{~K}$ to $1873 \mathrm{~K}$. To increase the thermal efficiency of the entire process, the enthalpy of hot flue gases is employed to heat the COG and air to combustion using a ceramic regenerator. Additional details of the heating system installed in the coke oven plant can be found in the works of Smolka et al. (2014) and Smolka et al. (2016).

\section{Mathematical model}

The governing equations that describe the phenomena of gas combustion in the coke oven furnace and heat transfer in the construction walls of the coke oven are formulated as follows (Anderson (1995)):

- Energy equation solved for temperature, which is coupled with the velocity field for fluids (mixture of gas, air and flue gases) and for the temperature fields in solid walls: 
Fig. 1 Views of the combustion chamber with the considered additional inlet arrangement: a from a side of the coking chamber, $\mathbf{b}$ from the top of the combustion chamber

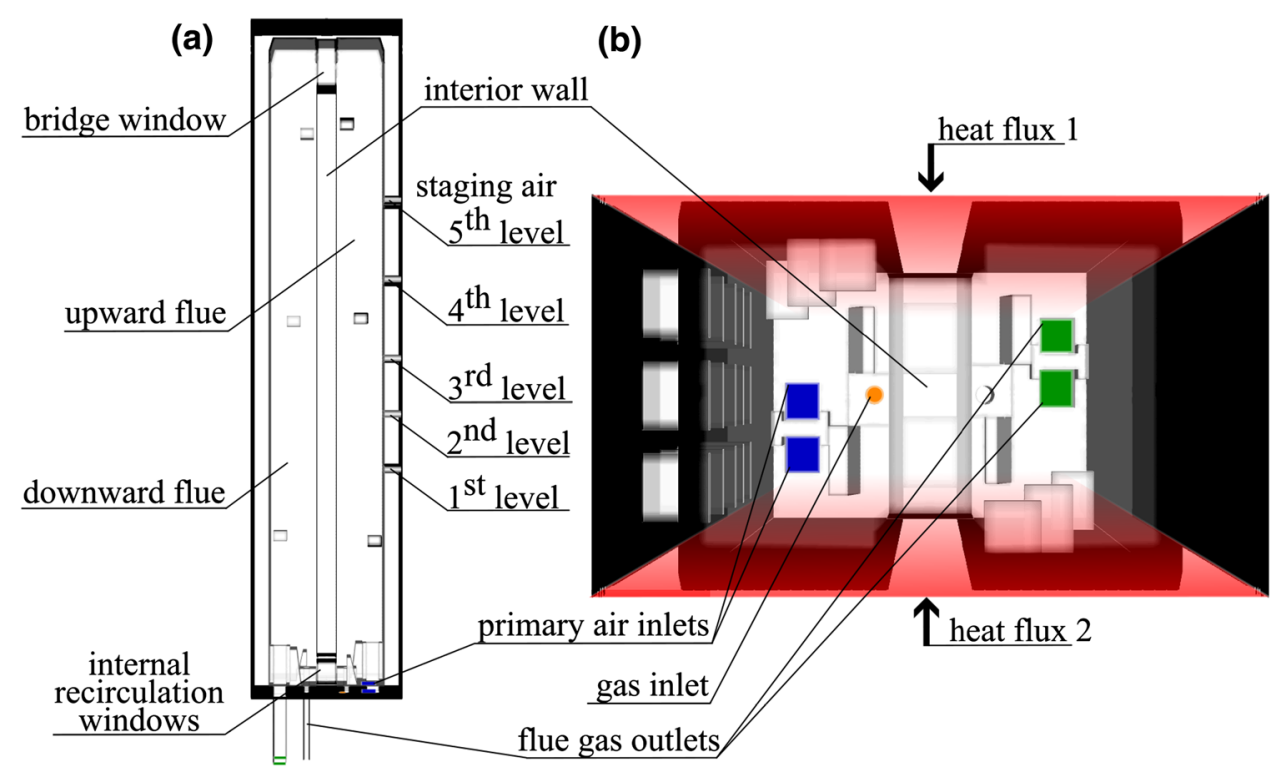

$\frac{\partial(\rho u)}{\partial t}+\nabla \cdot(\rho \mathbf{v} h)=\nabla \cdot(k \nabla T+\tau \cdot \mathbf{v})$$$
-\nabla \cdot\left(\sum_{i} h_{i} J_{i}\right)+S_{h}
$$

$J_{i}=-\rho D_{i} \nabla y_{i} \quad h=\sum_{i} h_{i} y_{i} \quad u=h-\frac{p}{\rho}$

$h_{i}=\int_{T_{r e f}}^{T} c_{p_{i}} d T$

where $\rho$ is the density, $u$ is the internal energy, $t$ is the time, $h$ is the specific enthalpy, $k$ is the effective thermal conductivity, $v$ is the velocity vector, $T$ is the temperature, $\tau$ is the effective stress tensor, $J$ is the diffusion mass flux, $S$ is the source term in the transport equation of the scalar quantity, $D$ is the mass diffusion coefficient, $y$ is the mass fraction, $c_{p}$ is the isobaric specific heat and $p$ is the pressure.

- Continuity equation solved for pressure coupled with the velocity vector of the fluids:

$\frac{\partial \rho}{\partial t}+\nabla \cdot(\rho \mathbf{v})=\sum_{i} S_{y_{i}}$

where $S_{\mathrm{yi}}$ is the mass source term of the $i$ th species.

- Momentum equation solved for the velocity vector components coupled with the pressure of the fluids:

$\frac{\partial(\rho \mathbf{v})}{\partial t}+\nabla \cdot(\rho \mathbf{v v})=-\nabla p+\nabla \cdot \overline{\bar{\tau}}+\rho \boldsymbol{g}+\boldsymbol{S}$

where $\boldsymbol{g}$ is the gravitational acceleration vector and $\boldsymbol{S}$ is the source term in the momentum transport equation.
- Turbulence (two-equation $\mathrm{k}-\varepsilon$ realisable turbulence) solved for the turbulence kinetic energy and the dissipation of the turbulence kinetic energy in the fluids:

$$
\begin{aligned}
\rho(\mathbf{v} \nabla \kappa)= & \nabla \cdot\left[\left(\mu+\frac{\mu_{T}}{\operatorname{Pr}_{k}}\right) \nabla \kappa\right]+S\left(\mu_{T}, \kappa, \mathbf{v}\right)-\rho \varepsilon \\
\rho(\mathbf{v} \nabla \varepsilon)= & \nabla \cdot\left[\left(\mu+\frac{\mu_{T}}{\operatorname{Pr}_{\varepsilon}}\right) \nabla \varepsilon\right]+C_{\varepsilon_{1}} \frac{\varepsilon}{\kappa} S\left(\mu_{T}, \kappa, \mathbf{v}\right) \\
& -C_{\varepsilon_{2}} \rho \frac{\varepsilon^{2}}{\kappa}
\end{aligned}
$$

where $\kappa$ is the turbulent kinetic energy, $\mu$ is the dynamic viscosity, $\operatorname{Pr}$ is the Prandtl number, $\varepsilon$ is the dissipation rate of the turbulent kinetic energy and $\mathrm{C}_{\varepsilon 1}$ and $\mathrm{C}_{\varepsilon 2}$ are the model constants. This model was compared with other two-equation models offered in commercial software in the previous works of Smolka et al. (2014) and Smolka et al. (2016) and successfully validated.

- Species transport. The number of these equations depends on the gas composition:

$\frac{\partial\left(\rho y_{\mathrm{i}}\right)}{\partial t}+\nabla \cdot\left(\rho \mathbf{v} y_{\mathrm{i}}\right)=\nabla \cdot \rho D_{\mathrm{i}} \nabla y_{\mathrm{i}}+S_{\mathrm{y}_{\mathrm{i}}}$

- Radiation (Discrete Ordinate model) solved for the radiative heat sources in the fluids and for the radiative heat fluxes on the surfaces of the solid walls 


$$
\begin{aligned}
& \nabla \cdot\left(I_{\lambda}(\boldsymbol{r}, \boldsymbol{s}) \boldsymbol{s}\right)+\left(a_{\lambda}+\sigma_{s}\right) I_{\lambda}(\boldsymbol{r}, \boldsymbol{s}) \\
& \quad=a_{\lambda} n^{2} I_{b \lambda}+\frac{\sigma_{s}}{4 \pi} \int_{0}^{4 \pi} I_{\lambda}\left(\boldsymbol{r}, \boldsymbol{s}^{\prime}\right) \Phi\left(\boldsymbol{s} \cdot \boldsymbol{s}^{\prime}\right) d \Phi^{\prime} \\
& \dot{q}_{r}=a \int_{\omega=4 \pi}\left(i-i_{b}\right) d \omega \\
& \frac{d i(r, \xi)}{d \xi}=-a i(r, \xi)+a i_{b}(r, \xi) \\
& \dot{q}_{\mathrm{v}, \mathrm{r}}=-\nabla \cdot \dot{q}_{\mathrm{r}}
\end{aligned}
$$

where $I$ is the intensity, $a$ is the absorption coefficient, $I_{\mathrm{b} \lambda}$ is the black body intensity, $\sigma$ is the Stefan-Boltzmann constant, $n$ is the refractive index, $s$ is the scattering direction vector and $\Phi$ is the phase coefficient.

All the material properties of the component gases that constitute the flue gases and the properties of the solid subdomain made of silica brick were described as being temperature dependent. A summary of the property data defined in the model is listed in Table 1.

For external walls at the bottom and top of the furnace, a convection boundary condition was defined. To simulate the influence of adjacent coking chambers, a heat flux boundary condition for the heating walls was employed. However, due to the reversing of the direction of the flue gases flow, the real coking process becomes unsteady. Hence, to simplify the numerical investigation, the value of the heat transferred through the heating walls was assumed to be an average value from the entire coking process. The value of $5000 \mathrm{~W} / \mathrm{m}^{2}$ was estimated and successfully validated in the authors' previous work on the coupled model of the heating system (Smolka et al. 2016). As a result of such an assumption, the numerical prediction of a typical amount of NO emitted over the entire cycle of coke oven furnace operation can be employed.

The mass flow boundary conditions, including temperature and gas compositions for the gas and air inlets, are shown in Table 2. These values were held constant in all the numerical test cases. However, the air mass flow rate
Table 2 Mass flow boundary conditions for gas and air inlets

\begin{tabular}{llll}
\hline Parameter/component & & Air & COG \\
\hline Mass flow rate, kg/s & & - & 0.002196 \\
Temperature, $\mathrm{K}$ & & 1473 & 1173 \\
Mass fraction & $\mathrm{O}_{2}$ & 0.20676 & 0.0209 \\
& $\mathrm{CO}_{2}$ & - & 0.1363 \\
& $\mathrm{H}_{2} \mathrm{O}$ & 0.01592 & 0.0342 \\
& $\mathrm{~N}_{2}$ & 0.77732 & 0.1049 \\
& $\mathrm{CO}$ & - & 0.2305 \\
& $\mathrm{H}_{2}$ & - & 0.0883 \\
& $\mathrm{CH}_{4}$ & - & 0.3090 \\
& $\mathrm{C}_{2} \mathrm{H}_{4}$ & - & 0.0476 \\
& $\mathrm{C}_{3} \mathrm{H}_{6}$ & - & 0.0204 \\
& $\mathrm{C}_{6} \mathrm{H}_{6}$ & - & 0.0079 \\
\hline
\end{tabular}

shown in this table was distributed among the primary and secondary inlets located in the bottom and side walls, respectively. All the tested configurations are discussed in "COG combustion with air staging" section and listed in Table 3.

\section{Chemical reactions and NO calculation model}

To properly simulate gas combustion phenomena, the eddy-dissipation model is appropriate as long as volumetric reactions are used. The two-step gas oxidation process is investigated in this paper. The following reaction mechanisms are introduced:

$$
\begin{aligned}
& \mathrm{CH}_{4}+1.5 \mathrm{O}_{2}=\mathrm{CO}+2 \mathrm{H}_{2} \mathrm{O} \\
& \mathrm{CO}+0.5 \mathrm{O}_{2}=\mathrm{CO}_{2} \\
& \mathrm{H}_{2}+0.5 \mathrm{O}_{2}=\mathrm{H}_{2} \mathrm{O} \\
& \mathrm{C}_{2} \mathrm{H}_{4}+2 \mathrm{O}_{2}=2 \mathrm{CO}+2 \mathrm{H}_{2} \mathrm{O} \\
& \mathrm{C}_{3} \mathrm{H}_{6}+3 \mathrm{O}_{2}=3 \mathrm{CO}+3 \mathrm{H}_{2} \mathrm{O} \\
& \mathrm{C}_{6} \mathrm{H}_{6}+4.5 \mathrm{O}_{2}=6 \mathrm{CO}+3 \mathrm{H}_{2} \mathrm{O}
\end{aligned}
$$

Table 1 Material properties of the flue gases and heating flue walls (temperatures are given in $\mathrm{K}$ )

\begin{tabular}{llc}
\hline Property & Fluid subdomain & Solid subdomain \\
\hline $\begin{array}{l}\text { Density } \\
\text { Thermal } \\
\text { conductivity }\end{array}$ & $\begin{array}{l}\text { Ideal gas model } \\
\text { Mass-weighted average for the flue gases and the polynomial functions of the temperature for the }\end{array}$ & 1800 \\
$\begin{array}{l}\text { Specific heat } \\
\text { Mass diffusivity }\end{array}$ & & $0.000,628 \cdot \mathrm{T}+0.9334$ \\
$\begin{array}{l}\text { Dynamic viscosity } \\
\text { Absorption } \\
\text { coefficient }\end{array}$ & Molar-weighted average based on temperature-dependent binary diffusivities & $0.25,116 \cdot \mathrm{T}+768.633$ \\
\hline
\end{tabular}


Table 3 The simulation scenarios for the $60 / 40$ and 70/30 distributions of the total air mass flow rate

\begin{tabular}{|c|c|c|c|c|c|c|c|c|c|c|c|c|}
\hline $\begin{array}{l}\text { Case no/ } \\
\text { Inlet no }\end{array}$ & 0 & 1 & 2 & 3 & 4 & 5 & 0 & 1 & 2 & 3 & 4 & 5 \\
\hline Reference & $100 \%$ & - & - & - & - & - & $100 \%$ & - & - & - & - & - \\
\hline 1 & $60 \%$ & - & - & $40 \%$ & - & - & $70 \%$ & - & - & $30 \%$ & - & - \\
\hline 2 & & - & - & - & $40 \%$ & - & & - & - & - & $30 \%$ & - \\
\hline 3 & & - & - & - & - & $40 \%$ & & - & - & - & $0 \%$ & $30 \%$ \\
\hline 4 & & - & - & $13 \%$ & $13 \%$ & $14 \%$ & & - & - & $10 \%$ & $10 \%$ & $10 \%$ \\
\hline 5 & & - & - & $24 \%$ & $12 \%$ & $4 \%$ & & - & - & $18 \%$ & $9 \%$ & $3 \%$ \\
\hline 6 & & - & - & $4 \%$ & $12 \%$ & $24 \%$ & & - & - & $3 \%$ & $9 \%$ & $18 \%$ \\
\hline 7 & & - & - & $10 \%$ & $20 \%$ & $10 \%$ & & - & - & $7.5 \%$ & $15 \%$ & $7.5 \%$ \\
\hline 8 & & - & - & $16 \%$ & $14 \%$ & $10 \%$ & & - & - & $12 \%$ & $10.5 \%$ & $7.5 \%$ \\
\hline 9 & & $8 \%$ & - & $14 \%$ & - & $18 \%$ & & $6 \%$ & - & $10.5 \%$ & - & $13.5 \%$ \\
\hline 10 & & $4 \%$ & - & $12 \%$ & - & $24 \%$ & & $3 \%$ & - & $9 \%$ & - & $18 \%$ \\
\hline
\end{tabular}

\section{Modelling the NO reduction process}

Three mechanisms of NO formation may be distinguished: thermal, prompt and fuel mechanisms. The thermal mechanism of NO formation (Zeldovich mechanism) occurs in a large-scale manner when the temperature exceeds $1600 \mathrm{~K}$ (Wilk 2002) or even $1700 \mathrm{~K}$ (Warnatz et al. 2006). At such a high temperature, nitrogen molecules can dissociate into two atoms, creating an opportunity to form NO molecules. The prompt mechanism relies on reactions between the nitrogen and hydrocarbon molecules. Radicals obtained in this manner can easily be oxidised to NO. The fuel-NO formation mechanism occurs when nitrogen is chemically bonded in a fuel.

A determination of the $\mathrm{NO}$ emission rates was performed using post-processing computations based on the temperature and flue gas mole fraction fields. Thermal and prompt NO generation mechanisms are assumed. The former mechanism is mostly responsible for modelling hydrocarbon radicals, such as $\mathrm{CH}$ and $\mathrm{CH}_{2}$, which can react very rapidly with nitrogen to produce NO. To simplify the employed numerical simulation, only the global kinetic parameters were used in the presented work to control the rate of NO production (Soete 1975).

The thermal mechanism contributes more to the overall NO formation process, mainly during gaseous fuel combustion. The source of pollutant formation is nitrogen provided to the combustion chamber by the oxidiser. The thermal mechanism makes a significant contribution to pollutant formation when the temperature in the combustion chamber exceeds $1923 \mathrm{~K}$, as presented by Kuo (2005). Under this condition, the nitrogen and oxygen from the oxidiser disassociate into atomic nitrogen and oxygen, which can produce NO. As a result, the thermal $\mathrm{NO}$ formation process is governed by two reversible reactions $\left(\mathrm{N}_{2}+\mathrm{O} \rightarrow \mathrm{NO}+\mathrm{N}, \mathrm{N}+\mathrm{O}_{2} \rightarrow \mathrm{NO}+\mathrm{O}\right)$, as proposed by Zeldovich (1946) and further extended by Lavoie et al. (1970) by considering the reaction of $\mathrm{N}$ with the radical hydroxyl $\mathrm{OH}(\mathrm{N}+\mathrm{OH} \rightarrow \mathrm{NO}+\mathrm{H})$. An important feature of the thermal $\mathrm{NO}$ mechanism is an assumption that the rates of formation and consumption of $\mathrm{N}$ atoms are equal. Hence, NO formation is defined as follows:

$\frac{d[N O]}{d t}=2 k_{f, 1}[O]\left[N_{2}\right] \frac{1-\frac{k_{r, r} k_{r, 2}[N O]^{2}}{k_{f, 1}\left[N_{2}\right] k_{f, 2}}}{1+\frac{k_{r, 1}[N O]}{k_{f, 2}\left[O_{2}\right]+k_{f, 3}[O H]}}$

where $\mathrm{k}_{\mathrm{f}, 1}, \mathrm{k}_{\mathrm{f}, 2}$ and $\mathrm{k}_{\mathrm{f}, 3}$ are the rate constants for the forward reactions, and $\mathrm{k}_{\mathrm{r}, 1}, \mathrm{k}_{\mathrm{r}, 2}$ and $\mathrm{k}_{\mathrm{r}, 3}$ are the rate constants for the reverse reactions. Equation (19) requires that the concentrations of $\mathrm{O}$ and $\mathrm{OH}$ be known. In the presented work, the partial equilibrium model described by Drake et al. (1987) was used to calculate the [O] and [OH] radicals using the following equations:

$$
\begin{aligned}
& {[O]=36.64 T^{1 / 2}\left[O_{2}\right]^{1 / 2} e^{-27,123 / T}} \\
& {[O H]=212.9 T^{-0.57} e^{-4,595 / T}[O]^{1 / 2}\left[H_{2} O\right]^{1 / 2}}
\end{aligned}
$$

The source term added to the NO transport equation due to the presence of the thermal NO is defined as follows:

$S_{\text {Thermal }, N O}=M_{w, N O} \frac{d[N O]}{d t}$

The presented results were computed using the prompt model developed based on the experimental data proposed by Bachmaier et al. (1973), which were evaluated for high hydrocarbon fuels and fuel-rich combustion conditions. These data were input into the original Soete (1975) prompt model, in which the final form of equation is defined as follows:

$\frac{d[N O]}{d t}=f k_{p r}^{\prime}[O 2]^{a}[N 2][F U E L] e^{-E / R T}$

where $f$ is the correction factor, $E$ is the activation energy, $a$ is the oxygen reaction order, FUEL are the fuel species and 
$k_{p r}^{\prime}$ is calculated as $6.4^{-6}(R T / p)^{a+1}$. The source term added to the NO transport equation due to the presence of the prompt NO is defined as follows:

$S_{\text {Prompt }, N O}=M_{w, N O} \frac{d[N O]}{d t}$

The correction factor $f$ in the above equation is defined as a function of the equivalence ratio $\varphi=1 / 1 \lambda$ and the fuel-carbon number $n$. The equation used for calculating the correction factor is as follows:

$f=4.75+0.0819 n-23.2 \varphi+32 \varphi^{2}-12.2 \varphi^{3}$

In the solution post-processing, three transport equations were solved for the mass fractions of $\mathrm{NO}, \mathrm{NH}_{3}$ and $\mathrm{HCN}$ :

$$
\frac{\partial}{\partial t}\left(\rho Y_{H C N}\right)+\nabla \cdot\left(\rho \bar{w} Y_{H C N}\right)=\nabla \cdot\left(\rho D Y_{H C N}\right)+S_{H C N}
$$

$$
\begin{aligned}
& \frac{\partial}{\partial t}\left(\rho Y_{N H 3}\right)+\nabla \cdot\left(\rho \bar{w} Y_{N H 3}\right)=\nabla \cdot\left(\rho D Y_{N H 3}\right)+S_{N H 3} \\
& \frac{\partial}{\partial t}\left(\rho Y_{N O}\right)+\nabla \cdot\left(\rho \bar{w} Y_{N O}\right)=\nabla \cdot\left(\rho D Y_{N O}\right)+S_{N O}
\end{aligned}
$$

where $Y$ is the mass fraction of $\mathrm{NO}, \mathrm{NH}_{3}$ and $\mathrm{HCN} ; S$ is the source term computed based on different NO mechanisms and $D$ is the effective diffusion coefficient. The sum of the computed mass fraction is the total $\mathrm{NO}$ emission. In the case of combustion process modelling using Ansys FLUENT, the transport equations (Eqs. (26), (27) and (28)), similar to the remaining governing equations, are averaged using the density-weighted approach, where the mean turbulent reaction rates $\bar{S}_{N O}, \bar{S}_{N H 3}$ and $\bar{S}_{H C N}$ are calculated using the probability density function (PDF) theorem defined in terms of the temperature. To calculate the PDF, the cumulative density function in terms of the variance has to be known. The variances can be calculated using a transport equation or via algebraic solution. For computational stability reasons, the second method was employed in this work.

\section{COG combustion with air staging}

Typical values of the air excess ratios used in the heating system of the PWR- 63 coke oven battery are in the range of 1.3 to 1.5 . In this paper, a single value of the air-to-fuel ratio of 1.5 was used. The theoretical basis for the approach of air staging for achieving combustion used in this paper was developed by Wilk (2002). The staging combustion performed in this study is based on the division of the total oxidiser mass flow rate into a primary and secondary stream. The primary air is used to form the reducing atmosphere in the first part of the combustion chamber.
This means that the air-to-fuel ratio at the beginning of the combustion process must not exceed unity.

In this work, a magnitude of the air-to-fuel ratio of 0.8 to 0.95 was assumed for the reference cases. Such an assumption defined the $60 / 40$ and 70/30 distributions of the total air mass flow. Those distributions are typical for air staging in industrial applications (Wilk 2002). This means that 60 or $70 \%$ of the total air mass flow rate was supplied to the bottom inlet, and the remaining 40 or $30 \%$ was distributed among additional inlets. Then, various approaches for the secondary air stream distribution were considered. Namely, five positions of the secondary inlet were numerically tested, as shown in Fig. 1. The air inlets are numbered from the bottom of the heating flue, where Inlet 0 is the primary air inlet and the side wall inlets are labelled from Inlet 1 to Inlet 5 .

Table 3 presents the percentages of the air mass flow distributions among all the air inlets for the 60/40 and $70 / 30$ distributions of the total air mass flow rate. In this work, the cases are distinguished based on the distribution of the secondary air stream. For example, in Case 1, $100 \%$ of the secondary air mass flow (for both the 60/40 and $70 / 30$ distributions of the total air mass flow) was supplied to Inlet 3 .

\section{Results and discussion}

Figure 2 presents the results obtained for the considered cases listed in Table 3. This figure shows the amount of NO obtained from the CFD calculations at the flue gas outlet for both the 60/40 and 70/30 distributions of the total air mass flow rate. In addition, the NO reduction of the staging air to combustion method is referred to as the base case, with the entire air mass flow rate supplied to the bottom inlet. In this case, the NO formation is 859 PPM. At the plant, decreased emission of $20 \%$ is noted when compared to the value obtained from the numerical model.

For the 60/40 distribution of the total air mass flow rate, the lowest rate of $\mathrm{NO}$ emission is found in Cases 1, 6 and 7. In Case 1, the NO reduction in comparison to the reference case is approximately $38 \%$. The highest NO emission is found in Cases 3, 5 and 9. However, the difference between these cases and the reference case remained substantial, exceeding $30 \%$.

For the 70/30 distribution of the total air mass flow distribution, two tendencies can generally be distinguished. The NO pollution is noticeably greater when the secondary air stream is supplied to one inlet only (Cases 1 through 3 ) than if the secondary air stream is divided among three inlets (Cases 4 through 10, excluding Case 9). For Cases 5, 6 and 7, the NO reduction exceeds $40 \%$. In other cases, this value still exceeds $30 \%$. 
Fig. 2 The NO emission in PPM for the 60/40 and 70/30 distributions of the total air mass flow rate

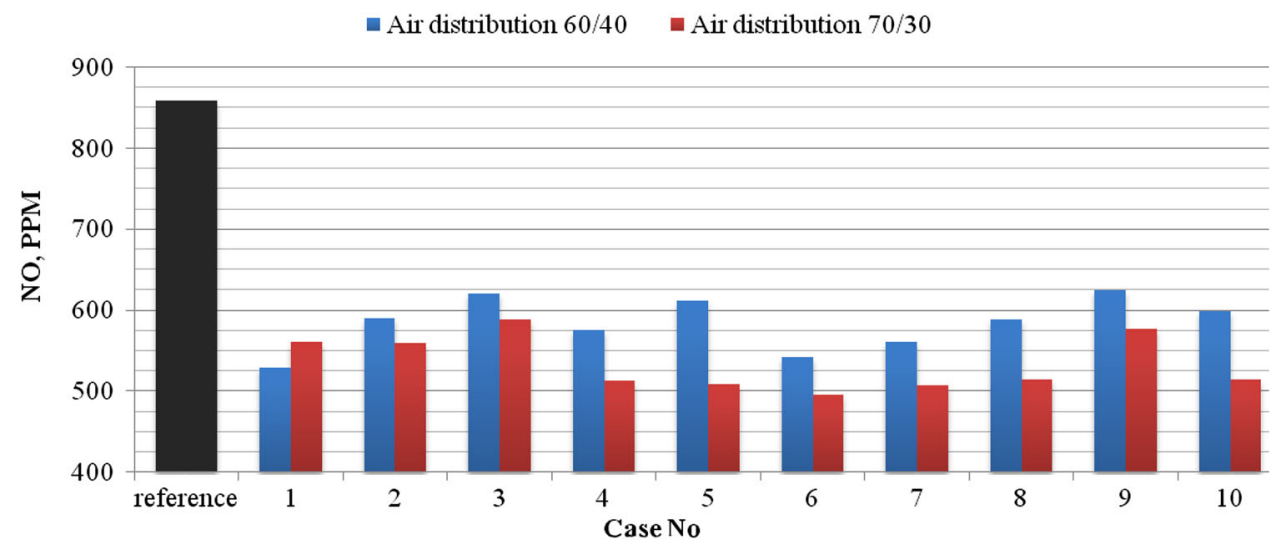

According to the NO emission results, the best options for the air staging implementation seemed to be Case 1 for the 60/40 air distribution and Case 6 for the 70/30 air distribution. These two cases differ in their NO emission reductions by only $6 \%$. In general, better and more uniform NO emission results were obtained for the 70/30 distribution than for the 60/40 distribution of the total air mass flow rate. This tendency is very noticeable for Cases 4 through 8 and Case 10 for the 70/30 distribution, where the largest difference in the NO emission is only 20 PPM. Based on the results presented in Fig. 2, the most significant decrease in NO pollution was observed for Case 6 , which provided beneficial outcomes for both total air mass flow distributions. Therefore, Case 6 was further considered as the most perspective case for both distributions (60/ 40 and 70/30). Using this base case, the mass flow rate contributions of the additional air at Inlets 3 through 5 were modified to find the air distribution variant that obtained the highest NO reduction. The computations were performed for both considered total air mass flow distributions. The data from those cases are depicted in Table 4 .

The results of the NO emission computations for those cases are shown in Fig. 3. Cases 6A and 6B, where the secondary air stream was supplied at three altitudes, provided almost the same outcome as Case 6. In Cases 6C and $6 \mathrm{D}$, where Inlet 3 was closed, the NO emission increase was almost $10 \%$ higher than that of Case 6 . These results had the same tendency for both considered total air mass flow distributions. Namely, the results were almost

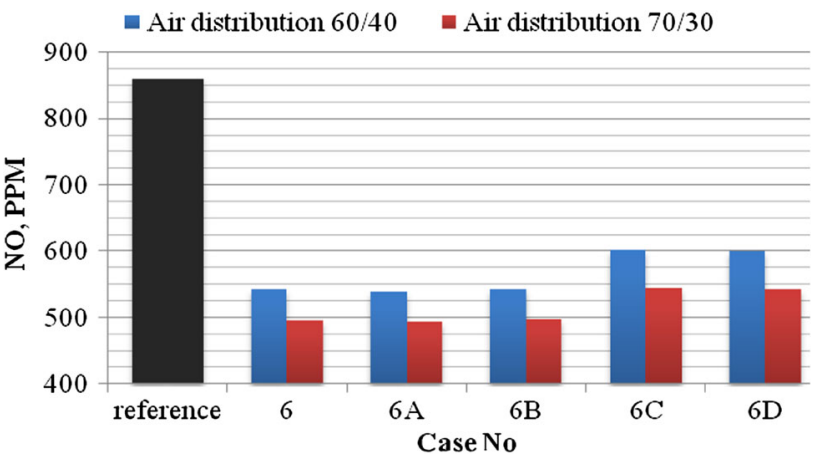

Fig. 3 The NO emission in PPM for Case 6 for the 60/40 and 70/30 distributions of the total air mass flow rate

identical between Cases 6A and 6B and Case 6, and higher $\mathrm{NO}$ emission was observed for Cases $6 \mathrm{C}$ and $6 \mathrm{D}$. Thus, the use of three additional inlets provided more efficient NO reductions in comparison to the cases where only two secondary inlets supplied the air.

For cases providing the highest $\mathrm{NO}$ emission reduction, i.e. Cases 1 and 6 , a study of the secondary air stream velocity influence on NO formation was performed. The air velocity is modified in two ways: by decreasing the inlet width by $30 \%$ and by decreasing the inlet height by $50 \%$. As in all the previous cases, the computations were performed for the $60 / 40$ and 70/30 total air mass flow distributions. The results of the secondary air velocity impact on the NO emission are presented for Cases 1 and 6 in Figs. 4 and 5 , respectively.
Table 4 The simulation scenario for the Case 6 analysis for the $60 / 40$ and $70 / 30$ distributions of the total air mass flow rate

\begin{tabular}{lllllllllllll}
\hline $\begin{array}{l}\text { Case/ } \\
\text { inlet }\end{array}$ & 0 & 1 & 2 & 3 & $\begin{array}{l}4 \\
(\%)\end{array}$ & $\begin{array}{l}5 \\
(\%)\end{array}$ & & & & & & \\
\hline 6 & $60 \%$ & - & - & $4 \%$ & 12 & 24 & $70 \%$ & - & - & $3 \%$ & 9 & 18 \\
$6 \mathrm{~A}$ & & - & - & $4 \%$ & 10 & 26 & & - & - & $3 \%$ & 7.5 & 19.5 \\
$6 \mathrm{~B}$ & & - & - & $4 \%$ & 14 & 22 & & - & - & $3 \%$ & 10.5 & 16.5 \\
$6 \mathrm{C}$ & & - & - & - & 14 & 26 & & - & - & - & 10.5 & 19.5 \\
$6 \mathrm{D}$ & & - & - & - & 12 & 28 & & - & - & - & 9 & 21 \\
\hline
\end{tabular}




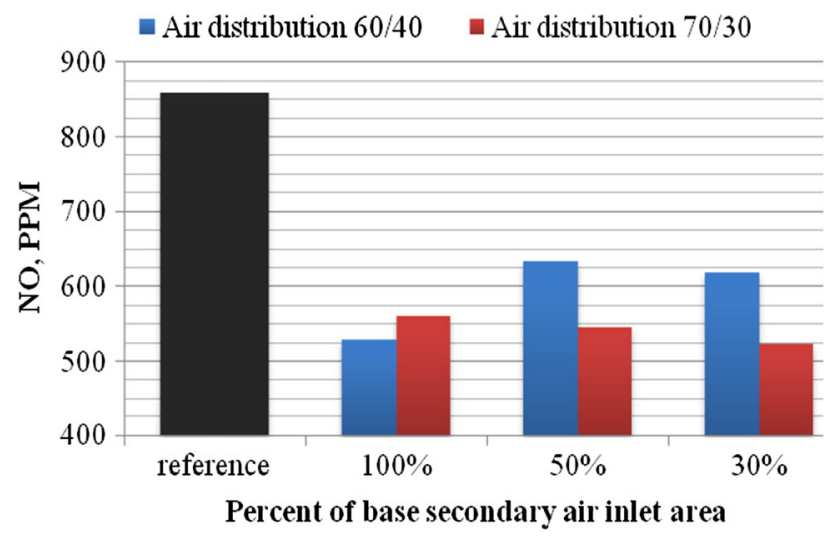

Fig. 4 The NO emission in PPM for various inlet velocities of the secondary air streams in Case 1 for the 60/40 and 70/30 distributions of the total air mass flow rate

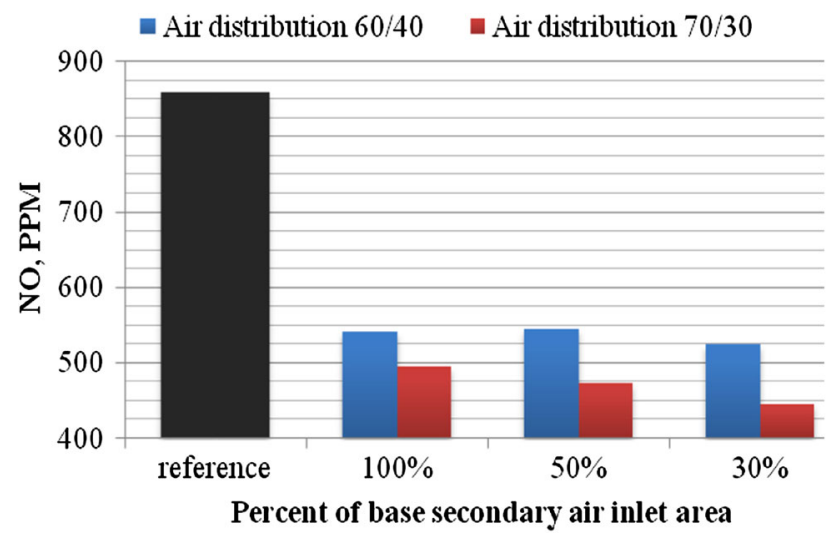

Fig. 5 The NO emission in PPM for various inlet velocities of the secondary air streams in Case 6 for the 60/40 and 70/30 distributions of the total air mass flow rate

In Fig. 4, the higher velocity in Case 1 caused the NO emission to increase for the $60 / 40$ distribution of the total air mass flow and the NO emission to decrease for the 70/30 distribution of the total air mass flow. In Fig. 5, the results obtained for Case 6 are presented. For the 60/40 distribution of the total air mass flow, the height decrease of the secondary air inlet area contributed to almost the same NO emission result. However, the smaller width of the secondary air inlet area caused a substantial NO formation reduction. For the 70/30 distribution of the total air mass flow, the decrease in the secondary air inlet area resulted in an $\mathrm{NO}$ emission decrease under both strategies.

In Fig. 6, a comparison of $\mathrm{NO}$ emission fields for data from Fig. 5 is presented. For the reference case presented in Fig. 6a, without staging combustion, the emission is the highest. The effect of air staging is noticeable for Case 6 with a standard additional inlet area. The NO emission significantly decreased across the entire heating flue domain, as presented in the cross-section through the gas
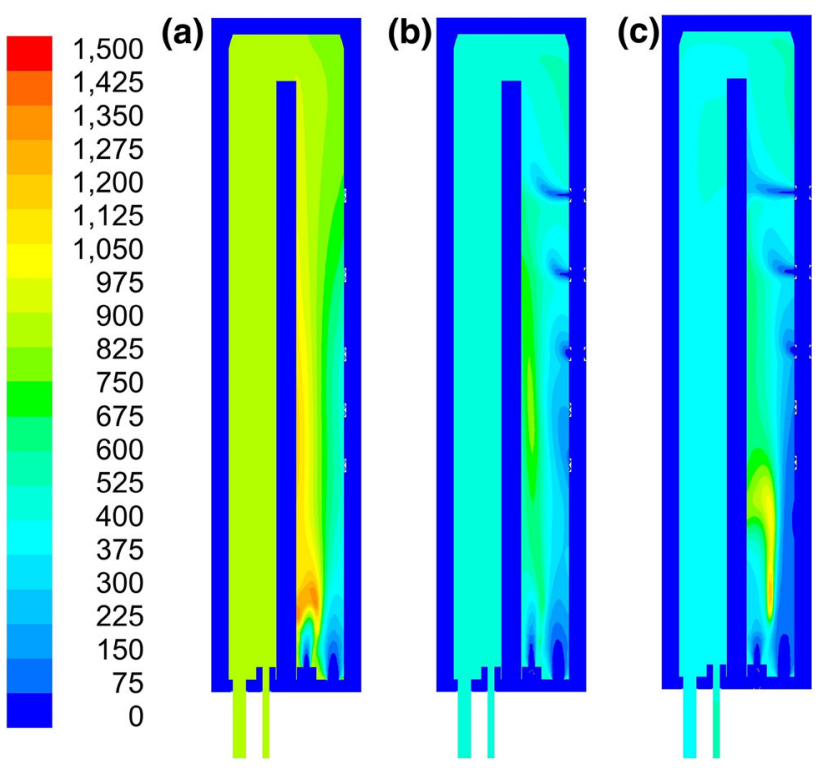

Fig. 6 The NO in PPM in the cross-sectional area shown in Fig. 1 for the a reference case, b case 6 with $100 \%$ secondary air inlet area for the 70/30 air distribution and case 6 with the secondary air inlet area decreased by $30 \%$ for the $70 / 30$ air distribution

inlet in this figure. The field with the reducing atmosphere is distinct in the lower part of the upward flue. For the case with reduced area inlets, presented in Figs. 4 and 5, a greater positive influence of staging air on NO formation can be observed. The only exception to this statement is Case 1 with the 60/40 distribution.

To summarise, a negative influence of the decreasing secondary inlet area was predicted for Case 1 with the 60/40 air flow distribution, as shown in Fig. 4. For Case 6, presented in Fig. 5, the inlet width reduction of the secondary inlets resulted in a $10 \%$ lower NO emission in comparison to the case with unmodified additional inlets.

\section{Conclusions}

A numerical investigation of the function of a coke oven heating system with air staging has been performed. A variety of secondary air mass flow distributions were considered for steady-state computations. In this study, the computational domain was limited to the heating flue only. However, to ensure model accuracy, the crucial value of the heat transfer through the heating walls was time averaged based on a fully coupled transient model of the coke oven battery.

The results showed a positive impact on the NO reduction in each considered case. Even the cases with a single secondary inlet obtained a reduced emission of $30 \%$ compared with the case without the air staging. In the case of additional air flow distributed between three secondary 
air inlets above a half height of the heating flue, the NO emission decreased by an additional $20 \%$. This result was consistent with the findings in the literature. Weiss et al. (2012) proved that staging on two levels is better than staging only on one level. In another work, Jin et al. (2013) showed that using three levels of staging was better than using only two levels.

In addition, a more beneficial effect on the $\mathrm{NO}$ emission for the 70/30 distribution compared to the $60 / 40$ distribution of the total air mass flow rate was presented. The results showed that an appropriate distribution and size of the staging air inlets can reduce NO formation by an additional $10 \%$ compared to the best case with a standard air inlet size.

The presented results are very promising for the Polish coke production sector. It becomes clear that the final distribution and size of the secondary inlets should be a matter of optimisation computations. However, future coke oven batteries or those retrofitted with the implemented air staging will potentially be able to meet stricter emission limits.

Acknowledgments The first four authors gratefully acknowledge the financial support of the European Union Project "Competent mechanical engineers for energetic sector" no. POKL.04.01.02-00131/12. The work of JS and WA was also partially supported by the statutory research fund of the Faculty of Power and Environmental Engineering.

Open Access This article is distributed under the terms of the Creative Commons Attribution 4.0 International License (http://crea tivecommons.org/licenses/by/4.0/), which permits unrestricted use, distribution, and reproduction in any medium, provided you give appropriate credit to the original author(s) and the source, provide a link to the Creative Commons license, and indicate if changes were made.

\section{References}

Anderson JD (1995) Computational fluid dynamics.The basics with applications. McGraw-Hill, New York

Annamalai K, Puri IK (2006) Combustion science and engineering. CRC Press, Boca Raton

Bachmaier F, Eberius KH, Just T (1973) The formation of nitric oxide and the detection of $\mathrm{HCN}$ in premixed hydrocarbon-air flames at 1 atmosphere. Combust Sci Technol 7:77-84

Boyd Fackler K, Karalus MF, Novosselov IV, Kramlich JC, Malte PC (2011) Experimental and numerical study of NOx formation from the lean premixed combustion of $\mathrm{CH} 4$ mixed with $\mathrm{CO}_{2}$ and $\mathrm{N}_{2}$. J Eng Gas Turbines Power 133:121502-121507

Cozzi F, Coghe A (2012) Effect of air staging on coaxial swirled natural gas flame. Exp Thermal Fluid Sci 43:32-39

Diez L, Cortes C, Pallares J (2008) Numerical investigation of NOx emissions from a tangentially-fired utility boiler under conventional and overfire air operation. Fuel 87:1259-1269

Directive 2001/80/EC of the European Parliament and of the Council (2001) On the limitation of emissions of certain pollutants into the air from large combustion plants. Off $\mathrm{J}$ Eur Commun 309:1-21
Drake M, Correa S, Pitz R, Shyy W, Fenimore C (1987) Superequilibrium and thermal nitric oxide formation in turbulent diffusion flames. Combust Flame 69:347-365

García-Gusano D, Cabal H, Lechón Y (2015) Evolution of NOx and $\mathrm{SO}_{2}$ emissions in Spain: ceilings versus taxes. Clean Technol Environ Policy 17:1997-2011

Hampartsoumian E, Folayan OO, Nimmo W, Gibbs BM (2003) Optimisation of $\mathrm{NOx}$ reduction in advanced coal reburning systems and the effect of coal type. Fuel 82:373-384

Higgins B, Yan L, Gadalla H, Meier J, Fareid T, Liu G, Milewicz M, Repczynski A, Ryding M, Blasiak W (2010) Biomass co-firing retrofit with ROFA for NOx reduction. Polish J Environ Study 19:1185-1197

Houshfar E, Wang L, Vähä-Savo N, Brink A, Løvås T (2014) Characterisation of $\mathrm{CO} / \mathrm{NO} / \mathrm{SO}_{2}$ emission and ash-forming elements from the combustion and pyrolysis process. Clean Technol Environ Policy 16:1339-1351

Ilamathi P, Selladurai V, Balamurugan K, Sathyanathan VT (2013) ANN-GA approach for predictive modelling and optimization. Clean Technol Environ Policy 15:125-131

Jin K, Feng Y, Zhang X, Wang M, Yang J, Ma X (2013) Simulation of transport phenomena in coke oven with staging combustion. Appl Therm Eng 58:354-362

Kang S, Kim Y, Lee KS (2009) Numerical simulation of structure and no formation of turbulent lean-premixed flames in gas turbine conditions. J Mech Sci Technol 23:3424-3435

Kumar A, Patil RS, Kumar AD, Kumar R (2016) Comparison of predicted vehicular pollution concentration with air quality standards for different time periods. Clean Technol Environ Policy March:1-11

Kuo K (2005) Principles of combustion. Wiley, Hoboken

Lavoie GA, Heywood JB, Keck JC (1970) Experimental and theoretical study of nitric oxide formation in internal combustion engines. Combust Sci Tech 4:313-326

Li S, Li Z, Jiang B, Chen Z, Zhang X (2015) Effect of secondary air mass flow rate on the airflow and combustion characteristics and NOx formation of the low-volatile coal-fired swirl burner. AsiaPac J Chem Eng. doi:10.1002/apj.1923

Loffler G, Sieber R, Haraseka M, Hofbauer H, Hauss R, Landauf J (2006) NOx formation in natural gas combustion-a new simplified reaction scheme for CFD calculations. Fuel 85:513-523

Ma L, Gharebaghi M, Porter R, Pourkashanian M, Jones JM, Williams A (2009) Modelling methods for co-fired pulverised fuel furnaces. Fuel 88:2448-2454

Miltner M, Makaruk A, Harasek M, Friedl A (2008) Computational fluid dynamic simulation of a solid biomass combustor: modelling approaches. Clean Technol Environ Policy 10:165-174

Ndibe C, Sporl R, Maier J, Scheffknecht G (2013) Experimental study of $\mathrm{NO}$ and $\mathrm{NO}_{2}$ formation in a PF oxy-fuel firing system. Fuel 107:749-756

Nimmo W, Singh S, Gibs BM, Williams PT (2008) The evaluation of waste tyre pulverised fuel for NOx reduction by reburning. Fuel 87:2893-2900

Panepinto D, Brizio E, Genon G (2014) Atmospheric pollutants and air quality effects: limitation costs and environmental advantages (a cost-benefit approach). Clean Technol Environ Policy 16:1805-1813

Smolka J, Fic A, Nowak AJ, Kosyrczyk L (2014) 3-D periodic CFD model of the heating system in a coke oven battery. Int $\mathrm{J}$ Numer Methods Heat Fluid Flow 24:891-906

Smolka J, Slupik L, Fic A, Nowak AJ, Kosyrczyk L (2016) 3-D coupled CFD model of a periodic operation of a heating flue and coke ovens in a coke oven battery. Fuel 165:94-104

Soete GD (1975) Overall reaction rates of $\mathrm{NO}$ and $\mathrm{N}_{2}$ formation from fuel nitrogen. 15th Symposium on combustion, vol 1, pp 1093-1102 
Techniques Report Best Available (2005) Reference document for the coke industry. Ministry of Environment, Warsaw (in Polish)

Wang X, Hu Z, Deng S, Xiong Y, Tan H (2014) Effect of biomass/coal co-firing and air staging on NOx emission and combustion efficiency in a drop tube furnace. Energy Procedia $16: 2331-2334$

Warnatz J, Maas U, Dibble RW (2006) Combustion. Berlin, Germany

Weiss C, Rieger J, Rummer B (2012) Formation and control of nitrogen oxide in the heating system of a coke oven. Environ Eng Sci 29:555-562
Wilk RK (2002) Low-emission combustion. Silesian University of Technology Publishing House, Gliwice

Zeldovich YB (1946) The oxidation of nitrogen in combustion explosions. Acta Physicochim U.S.S.R. 21:577-628

Zhou H, Yang Y, Liu H, Hang Q (2014) Numerical simulation of the combustion characteristics of a low NOx swirl burner: influence of the primary air pipe. Fuel 130:168-176 